\title{
An investigation of the ultrasonic joining process parameters effect on the mechanical properties of metal-composite hybrid joints
}

\author{
E. E. Feistauer ${ }^{1}$ - J. F. dos Santos ${ }^{1} \cdot$ S. T. Amancio-Filho ${ }^{2}$ (B) \\ Received: 2 December 2019 / Accepted: 18 May 2020 / Published online: 27 May 2020 \\ (C) The Author(s) 2020
}

\begin{abstract}
The ultrasonic joining process was recently introduced as an alternative concept to join through-the-thickness reinforced metalcomposite hybrid structures. In this work, the investigation of joining process parameters effect on the joint mechanical performance of Ti-6Al-4V-glass-fiber-reinforced polyetherimide overlap joints was carried out by Box-Behnken design of experiments. The individual and combined effects of joining energy, sonotrode oscillation amplitude, and joining pressure on the ultimate lap shear force were elucidated by response surfaces method and analysis of variance. As a result of this study, a set of optimized joining parameters were obtained to produce joints with high ultimate lap shear force. The obtained reliable reduced model $\left(R^{2}=82 \%\right)$ displays a major influence of joining energy (25.3\%) and sonotrode oscillation amplitude (21.2\%) on the joint mechanical performance. Two-way interaction response surfaces were used to support strategies to optimize the maximum ultimate lap shear force. By comparing the optimized joint condition produced in this work with previously published results an improvement of $79 \%$ in ultimate lap shear force was attained, thereby, proving the potential of the proposed process optimization procedure.
\end{abstract}

Keywords Metal-composite hybrid structures - Ultrasonic joining - Box-Behnken design - Mechanical connections · Polyetherimide $\cdot$ Titanium alloys

\section{Introduction}

The application of multi-material structures has been increasing over the last years, especially in the transportation sector. The precise selection of materials as well as the synergetic combination of different materials in the same optimized structure can lead to considerable improvements in vehicle's structural weight, damage tolerance, and thereby safety. Therefore, adequate lightweight materials selection supports the transportation sector to

Recommended for publication by Commission III - Resistance Welding, Solid State Welding, and Allied Joining Process

S. T. Amancio-Filho

sergio.amancio@tugraz.at

1 Helmholtz-Zentrum Geesthacht, Centre for Materials and Coastal Research, Institute of Materials Research, Materials Mechanics, Solid State Joining Processes, Geesthacht, Germany

2 Institute of Materials Science, Joining and Forming, BMK Endowed Professorship for Aviation, Graz University of Technology, Kopernikusgasse 24/1, 8010 Graz, Austria comply with strict environmental regulation regarding greenhouse gas emissions [1,2]. Although the idea of combining dissimilar materials in the same functional structure has the potential of improving transportation systems, it raises problems related to materials physicalchemical dissimilarities [3, 4]. Thus, joints between metal and composite usually are the weakest spot in metalcomposite hybrid structures. Furthermore, state-of-the-art metal-composite overlap joints-e.g., joined by adhesive bonding - usually present brittle failure due to their reduced out-of-plane strength.

Recent developments on the joining of metal-composite hybrid structures $[4,5]$ suggest that through-the-thickness reinforcement (TTR) integrated on the metal part surface can increase the mechanical performance of metal-composite overlap joints. Such concepts are classified in a new class of joining technologies called direct assembling (DA). In this joining approach, the surface of the metallic part is modified by a structuring technique, upon which the composite is directed assembled layer-by-layer [6-10]. In order to decrease the assembling cycles, while still producing joints improved out-of-plane performance, the ultrasonic joining (U-Joining) 
concept has been introduced [11-13]. This new DA approach can produce TTR metal-composite hybrid joints in a fast and energy efficient joining manner.

U-Joining uses ultrasonic energy to join metallic parts with integrated pins - manufactured for instance by metal injection molding (MIM) - to fiber-reinforced thermoplastic composites. Joining is accomplished through two major bonding mechanisms activated by ultrasonic frictional heating: mechanical interlocking and adhesion forces $[5,12]$. The first is a result of a TTR effect between metallic pins and composite, whereas adhesive forces are formed at the metal-composite interface after joint consolidation. However, the process feasibility has been already shown; there are several engineering and scientific knowledge gaps regarding the understanding of the joining process-microstructure-mechanical properties correlation in hybrid joints assembled by the U-Joining. Hence, in this paper, a Box-Behnken design of experiment (BBD) was applied to further elucidate the effect of joining parameter changes on the joint mechanical properties, providing a reliable statistical model for the fundamental understanding of the correlation between U-Joining and hybrid joint mechanical performance, and a set of optimized joining parameters.

\section{Basics of the U-Joining process}

U-Joining is a new direct assembling process developed at Helmholtz-Zentrum Geesthacht, Germany [14, 15]. The process uses ultrasonic energy to joint surface-structured metallic parts to fiber-reinforced thermoplastics composites. The joining process starts with the placing of the joining parts between the anvil and non-consumable joining tool, as shown in Fig. 1 (step 1), with the surface-structured pins of the metallic part in contact with the composite upper surface. As soon as the sonotrode starts to vibrate in a back-and-forth motion (step 2), frictional heat is created at the interface between pins and composite. As a result of the combined effect of frictional heat and pressure applied vertically by the sonotrode the composite matrix below the pins is locally softened. This allows the TTR to smoothly penetrate the composite, as shown in step 3 .

The pin's feeding and local decrease in composite matrix viscosity induce the formation of a squeezed flow of softened polymer, as shown in the detailed in step 3. This material volume flows upwards and wets out the metallic surface after the complete penetration of the pins. Once the pins are completed inserted in the composite, the consolidation phase starts (step 4). This phase can be either performed under pressure or not. However, a consolidation cycle under pressure is recommended to accommodate for differential shrinkage between the materials. In the last stage of the joining cycle (step 5), the sonotrode is retracted and the process ended.

The U-Joining joints are bonded by two fundamental mechanisms: mechanical interlocking due to the TTR and adhesive forces creates after the consolidation of the softened polymer layer at the interface. In addition, mechanical interlocking at microscale has also been reported [12] at the interface between metal and composite due to a high surface roughness led on the MIMStruct part after sintering.

U-Joining process parameters play a significant role in the joint formation and resultant joint mechanical performance. Process parameters depend on the joining equipment used and assembling variant and are similar to those described for ultrasonic welding of similar metals [16] or thermoplastics $[17,18]$. The core set of process parameters include joining energy $\left(E_{J}\right)$, sonotrode oscillation amplitude $\left(A_{0}\right)$, joining pressure $\left(J_{p}\right)$, clamping pressure $\left(C_{p}\right.$, the pressure applied by the sonotrode to hold the overlapping parts against the anvil during joint consolidation), and joining cycle $(t)$. Apart from

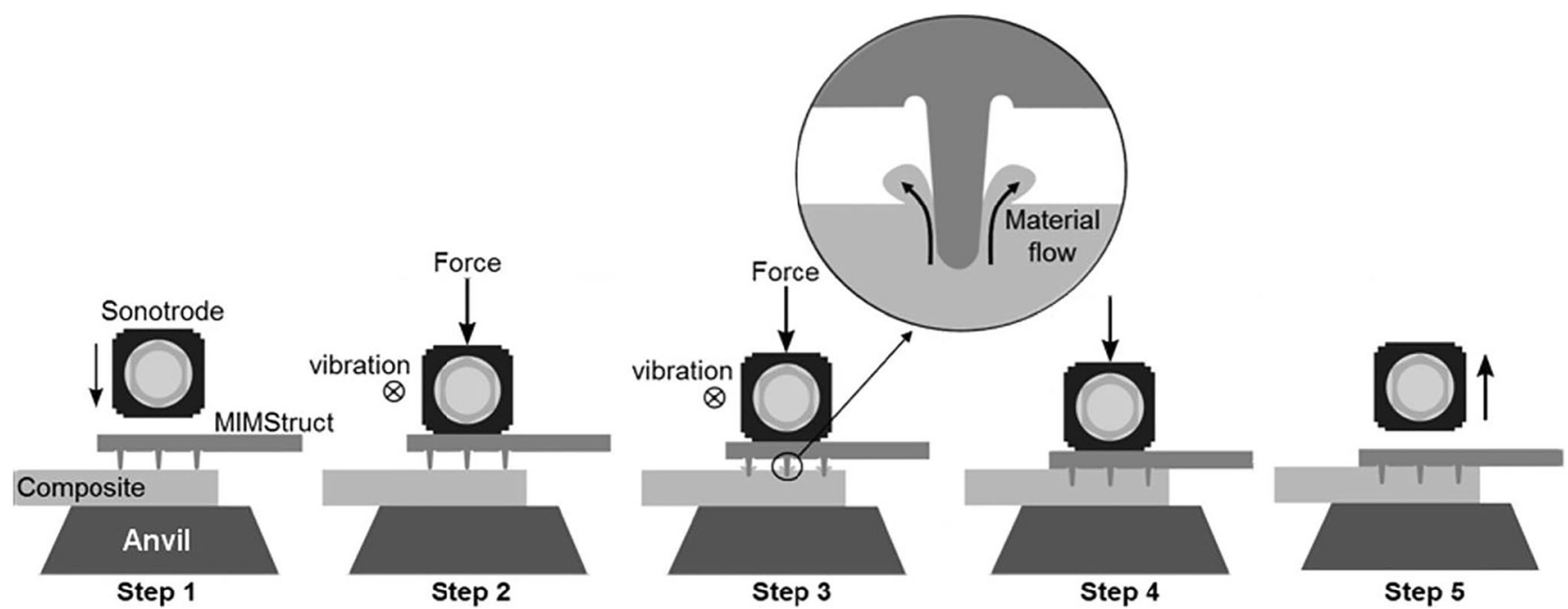

Fig. 1 Schematic representation U-Joining process steps. The process steps consist of joining parts placement between the sonotrode and anvil (1), application of ultrasonic vibration and axial force (2), softening of the composite matrix and onset of pin penetration (3), consolidation phase (4), and sonotrode retraction (5), adapted from [12] 
that, materials properties (such as composite fiber content or mechanical properties of the TTR), thickness, density, geometry, and distribution of TTR elements are expected to have a significant influence on the joining process. When the Ujoining is carried out under energy-controlled mode, the ultrasonic vibration is maintained constant until the preset value of energy is achieved, regardless the initial set up of the remaining parameters [18]. In such case, the energy delivering is moderated during the joining by the integral of power over time $[17,18]$-i.e., $E_{J}=P \times t$. Therefore, $t$ is a dependent variable automatically adjusted by the joining system to deliver the required amount of preset $E_{J}[16]$.

The power required to start and keep the sonotrode vibration depend on the preset $J_{F}$ (normal force applied parallel to the sonotrode vibration), $A_{0}$ and dynamic coefficient of friction between the materials. When the energy level integrated by the joining system reaches the specified $E_{J}$, the sonotrode vibration is stopped. Some implications can be drawn from the control mechanisms used by the joining system. For a fixed value of setup $E_{J}$, the higher the $\mathrm{A}_{0}$ and $\mathrm{J}_{\mathrm{P}}$, the higher is the power required by the system and, consequently faster will be the joining cycles. Nonetheless, the product of parameters amplitude $A_{0}$ and $\mathrm{J}_{\mathrm{P}}$ controls the power required to start and maintain the sonotrode oscillation during the joining, which affects the energy consumption. Moreover, one must take into consideration the stiffness and mechanical properties of the TTR elements when selecting the $J_{F}$, to avoid their deflection by plastic deformation.

\section{Materials and methods}

\subsection{Base materials}

For the process optimization and understanding of the joining process-mechanical properties correlation, hybrid joints with metal injection molding (MIM) surfacestructured Ti-6Al-4V and glass-fiber reinforced polyetherimide were produced. Both materials were selected in this study because they are certified materials used in primary and secondary aircraft structures. Moreover, their joinability by ultrasonic energy is less explored in the literature and deserved to be studied. The joint metallic part was manufactured according to the MIMStructuring concept as previously presented in [12, 19]. Figure 2 illustrates the as-sintered Ti-6Al-4V part (also referred as MIMStruct) with six round-tip conical pins used in this work. The part has $15.5 \times 35 \times 3 \mathrm{~mm}$ and the pins are $3 \pm$ $0.02 \mathrm{~mm}$ height (Fig. 2a). The detail view A displays the pins undercuts, which has a radius of $0.4 \mathrm{~mm}$ and were created to displace the stress concentration from the pin base towards the base plate and improve the mechanical interlocking between the materials. Relevant physical and mechanical properties of the used MIMStruct part are presented in Table 1.

As a polymeric part, 6.35-mm glass-fiber-reinforced polyetherimide laminates with a content of $50 \%$ in volume of resin (GF-PEI) and ply stacking sequence of $[0,90]_{28}$ from TENCATE (CETEX®PEI) were used. GFPEI is an amorphous polyetherimide thermoplastic composite qualified by the aircraft industry for primary and secondary structural application [22, 23]. Plates measuring $15.5 \times 35 \times 6.35 \mathrm{~mm}$ were machined to produce the joining parts, as shown in Fig. 3a. The microstructure of GF-PEI is presented in Fig. 3b, and it consists of warp fiber oriented in $0^{\circ}$ and weft fiber interlaced at $90^{\circ}$, following a Harness-Satin weave pattern. Relevant physical and mechanical properties of the GF-PEI laminates are presented in Table 2. The GF-PEI present outstanding mechanical performance and thermal stability, a thermal expansion coefficient five times higher compared with the Ti-6Al-4V, and thermal conductivity 31 times lower.

\subsection{Joining procedure}

The U-Joining process was carried out using a commercially available metal ultrasonic welding system (Ultraweld L20, Branson Ultrasonics). The joining equipment operates with a fixed sonotrode oscillation frequency of $20 \mathrm{kHz}$, output power of the generator of $4 \mathrm{~kW}$, and it was controlled by the so-called energy mode - i.e., the sonotrode vibration is kept constant until the user preset energy value is delivered. Under this control mode, the joining system will operate in a closed-loop. The joining cycle is automatically adjusted by the control unit to deliver the pre-set value of energy $\left(\mathrm{E}_{\mathrm{J}}\right)$ according to Eq. 1 [25].

$E_{J}=P \times t$

where $P$ is the power and $t$ is the joining cycle time. The joining system integrates the used power in intervals of one millisecond and adjusts the remaining joining cycle to deliver the energy value. Power is a function of resultant force and velocity of the sonotrode vibration, while force is determined by multiplying the cylinder surface area by the sonotrode manometric pressure (i.e., the joining pressure, $J_{P}$ ). The velocity, on the other hand, can be derived from the frequency and amplitude $\left(\mathrm{A}_{0}\right)$ [25].

To accommodate the materials between the joining tool and the anvil a specific sample holder was designed. It consists of two parts: a fixed holder and an adjustable holder. The composite part of the joint is placed in the fixed holder slot, as shown in Fig. 4a. After that, the surface-structured metallic part is placed on top of the composite, with the pin tips in contact with the composite surface. The sample holder adjustable part can slip on the 
a

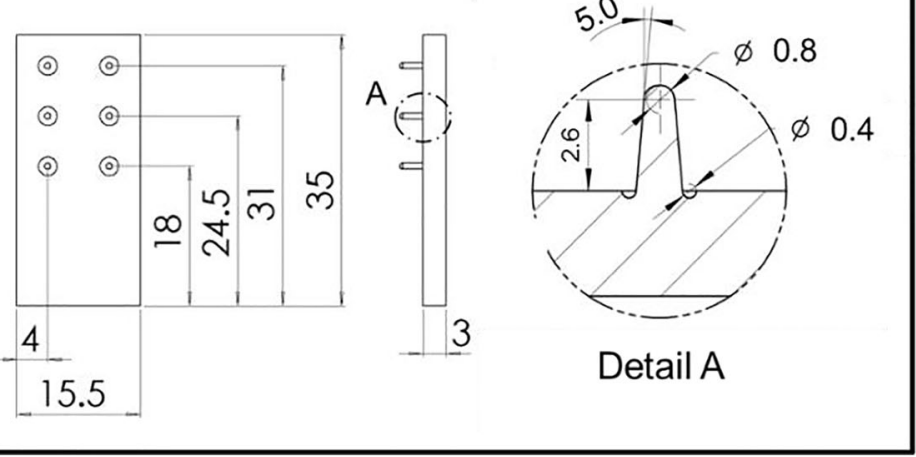

b

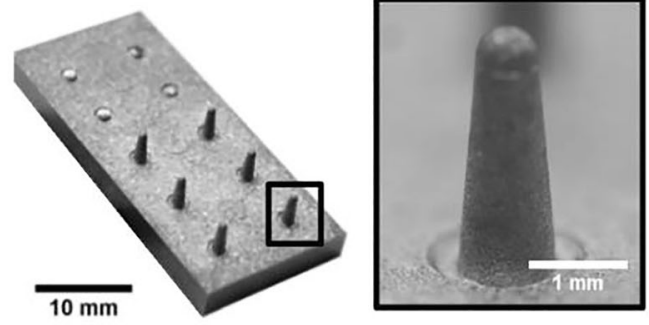

Fig. 2 Geometry of the used MIM-structured Ti-6Al-4V parts (a) and a picture of the as-sintered six-pin part with a detailed of a round-tip conical pin (b)

fixed holder and, thereby, adjust the overlapped area between the composite and metallic part. Hence, joints with a different overlapped areas can be produced, while keeping it well align beneath the joining tool and thereby distributing the joining pressure homogeneously to all the surfacestructured pins. A joining tool with wavy surface pattern (Fig. 5) was designed to better grip the metallic part of the joint, preventing slippage between the joint metallic part and the tool. Knurled pattern was applied in the anvil. The material used to manufacture the tools is a maraging steel (materials designation DIN 1.6358). This low carbon hardenable martensitic steel was heat-treated after tool machining to reach high hardness values (54 HRC). Subsequently, it underwent a nitriding surface treatment to further improve its wear resistance.

\subsection{Joint geometry}

Customized single lap joints were used for the U-Joining process understanding and optimization. The hybrid joint geometry is presented in Fig. 6. The joints are thought-the-thickness reinforced with six-pins structured on the metallic part surface. The proposed geometry is defined by injection molding tool available at HZG facilities, which was first design for preliminary development of the U-Joining process and proof of concept. The joints presented an overlapped area of $21 \times 15.5 \mathrm{~mm}$ and a total length of $49 \mathrm{~mm}$. In addition, the nominal thickness at the overlap area is $9.35 \mathrm{~mm}$.

\subsection{Microstructural characterization}

The typical U-Joining microstructural features presented in this work were obtained by scanning electron microscopy using a Quanta ${ }^{\mathrm{TM}} 650$ equipment by FEG. The measurement was carried out with $10 \mathrm{kV}$, spot size of 3.5 , and a working distance of $10 \mathrm{~mm}$ combining secondary and backscattered electrons. Prior to the SEM analysis, the polished samples were gold sputtered using a Q150R ES equipment from Quorum Technologies Ltd., England, with a current of $60 \mathrm{~mA}$ for $30 \mathrm{~s}$.

\subsection{Non-destructive characterization by X-ray micro- computed tomography}

Prior to mechanical testing, non-destructive tests using microcomputed tomography $(\mu \mathrm{CT})$ were performed to evaluate the integrity of the TTR and joint formation. Two parameters were measured by $\mu \mathrm{CT}$ : pin deflection (Fig. 7a) and lack of penetration (LoP, measured as schematically represented in Fig. 7b). The equipment used was a Y. Cougar, Feinfocus Xray system from XYLON International. The measurement parameters were set as follows: quality scan mode, a number of projections equal to 360 , integration time of $1 \mathrm{~s}$, voltage of $65 \mathrm{kV}$, and current of $70 \mu \mathrm{A}$. The reconstructed $\mu \mathrm{CT} 3 \mathrm{D}$ models were obtained and analyzed using the software VGStudio 3.0. The metallic part of the joints was segmented the by thresholding using the gray-level histogram.

Table 1 Selected physical and mechanical properties of the MIM-structured Ti-6Al-4V parts

\begin{tabular}{llllll}
\hline $\begin{array}{l}\text { Ti-6Al-4V } \\
\text { condition }\end{array}$ & $\begin{array}{l}\text { Melting point } \\
\left({ }^{\circ} \mathrm{C}\right)\end{array}$ & $\begin{array}{l}\text { Thermal expansion } \\
\text { coefficient }\left(\mathrm{K}^{-1}\right)\end{array}$ & $\begin{array}{l}\text { Thermal conductivity } \\
\left(\mathrm{W} \mathrm{m}^{-1} \mathrm{~K}^{-1}\right)\end{array}$ & $\begin{array}{l}\text { Yield stress } \\
(\mathrm{MPa})\end{array}$ & $\begin{array}{l}\text { Ultimate tensile strength } \\
(\mathrm{MPa})\end{array}$ \\
\hline As sintered & $1650^{\mathrm{a}}$ & $11 \times 10^{-6} \mathrm{a}$ & $7.0^{\mathrm{a}}$ & $748 \pm 3^{\mathrm{b}}$ & $861 \pm 3^{\mathrm{b}}$ \\
$(\%)$
\end{tabular}

${ }^{\text {a }}$ Data from the literature [20]

${ }^{\mathrm{b}}$ Experimentally obtained according to ISO 2740 [21] 
a

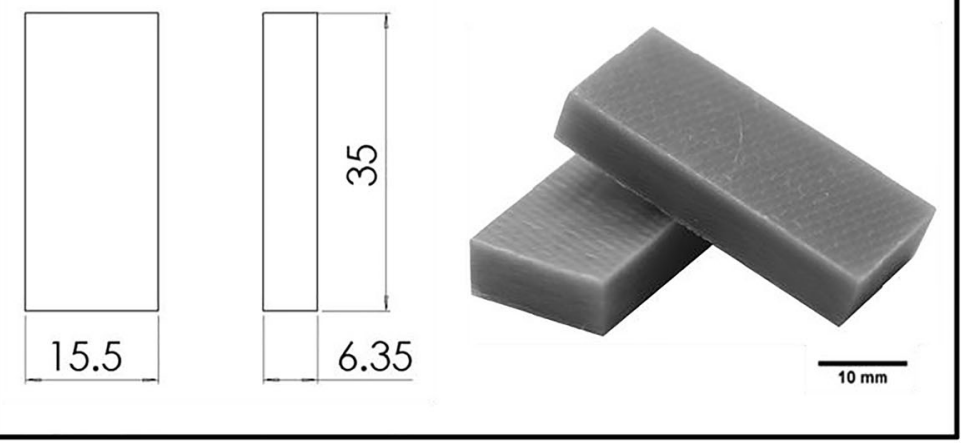

b

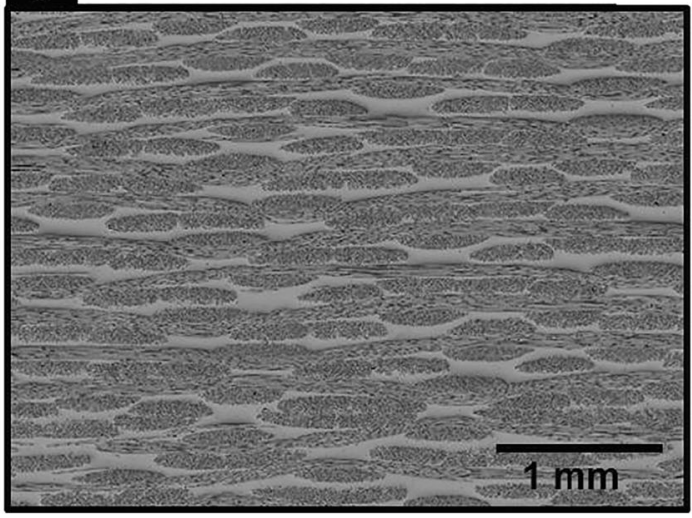

Fig. 3 Geometry of the GF-PEI parts (a) and its microstructure (b)

\subsection{Design of experiments and statistical analysis of the joint mechanical performance}

\subsubsection{Box-Behnken design of experiment}

Box-Behnken design (BBD) is a tool for multivariable optimization and comprises of incomplete three-level factorial designs. In BBD designs, the sample size is kept to a value sufficient for the estimation of second-order polynomial functions $[26,27]$. Thus, offering the maximum efficiency for processes optimization in comparison with central composite design (CCD) when three factors and three levels are involved [28]. An essential feature of BBD is that experiments under extreme conditions, combining factors at highest or lowest levels are avoided [29]. This corresponds to an experimental advantage in the case of joining processes since combinations of process parameters at those levels usually result in extreme operating conditions for joining equipment. The number of experiments required for BBD is defined by the Eq. 2 .

$N=2 k(k-1)+C_{0}$

where $k$ is the number of factors and $C_{0}$ is the number of replicate at the design central point. In this work, three factors were consider for the BBD: joining energy $\left(E_{J}\right)$, sonotrode oscillation amplitude $\left(A_{0}\right)$, and joining pressure $\left(J_{P}\right)$. In order to simplify the statistical modeling, the factor clamping pressure $\left(C_{P}\right)$ was kept always at the same level of $J_{P}$. Therefore, it could be removed from the experimental investigation. The selected factors were varied in three different levels and three replicates were performed at the central point in order to estimate the experimental error. In total, according to Eq. 2, 15 runs were performed for the proposed design.

The effect of the mentioned process parameters on two responses was investigated, i.e., ultimate lap shear force (ULFS) and LoP. Table 3 presents the complete set of factors and variation levels investigated in this work.

The complete matrix of BBD experiments is presented in Table 4. Although the tests in this table are presented in sequential order, all the runs were adequately randomized before the joining. Thus, ensuring that the observation and errors are independently distributed random variables [30].

The response $Y$ (i.e., ULSF or LoP) is estimated from a non-linear quadratic model as follows:

$$
\begin{aligned}
Y= & \beta_{0}+\beta_{1} x_{1}+\beta_{2} x_{2}+\beta_{3} x_{3}+\beta_{12} x_{1} x_{2}+\beta_{13} x_{1} x_{3} \\
& +\beta_{23} x_{2} x_{3}+\beta_{11} x_{1}^{2}+\beta_{22} x_{2}^{2}+\beta_{33} x_{3}^{2}
\end{aligned}
$$

where $Y$ is the measured output, $\beta_{0}$ is the intercept, $\beta_{1}, \beta_{2}$, and $\beta_{3}$ are linear regression coefficients, $\beta_{12}, \beta_{12}$, and, $\beta_{23}$ are the interactive regression coefficient $\beta_{11}, \beta_{22}$, and, $\beta_{33}$ are quadratic regression coefficients. $x_{1}, x_{2}$, and $x_{3}$ are the normalized factors, codded factors $E_{J}, A_{0}$, and $J_{P}$, respectively [29, 31, 32].
Table 2 Selected physical and mechanical properties of GF-PEI

\begin{tabular}{llllll}
\hline $\begin{array}{l}\text { Glass transition } \\
\text { temperature } \\
(\mathrm{DSC})\left({ }^{\circ} \mathrm{C}\right)\end{array}$ & $\begin{array}{l}\text { Onset thermal } \\
\text { decomposition } \\
(\mathrm{TGA})\left({ }^{\circ} \mathrm{C}\right)\end{array}$ & $\begin{array}{l}\text { Thermal } \\
\text { expansion } \\
\text { coefficient } \\
\left(\mathrm{K}^{-1}\right)\end{array}$ & $\begin{array}{l}\text { Thermal } \\
\text { conductivity } \\
\left(\mathrm{W} \mathrm{m}{ }^{-1} \mathrm{~K}^{-1}\right)\end{array}$ & $\begin{array}{l}\text { Tensile } \\
\text { strength } \\
\text { warp (MPa) }\end{array}$ & $\begin{array}{l}\text { Tensile } \\
\text { strength } \\
\text { weft (MPa) }\end{array}$ \\
\hline $214.1 \pm 0.7^{\mathrm{a}}$ & $531 \pm 1^{\mathrm{a}}$ & $50 \times 10^{-6 \mathrm{~b}}$ & $0.22^{\mathrm{b}}$ & $484^{\mathrm{b}}$ & $445^{\mathrm{b}}$ \\
\hline
\end{tabular}

${ }^{\text {a }}$ Experimentally obtained

${ }^{\mathrm{b}}$ Data from the literature [22, 24] 
a

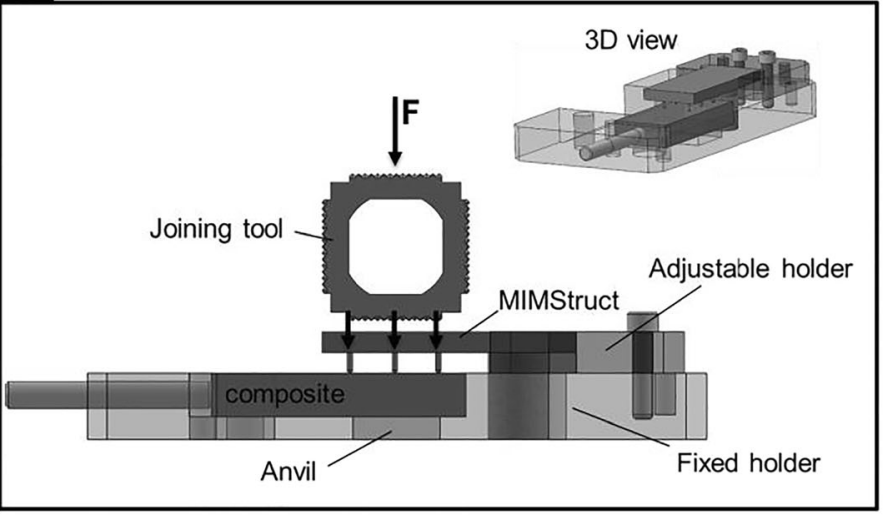

b

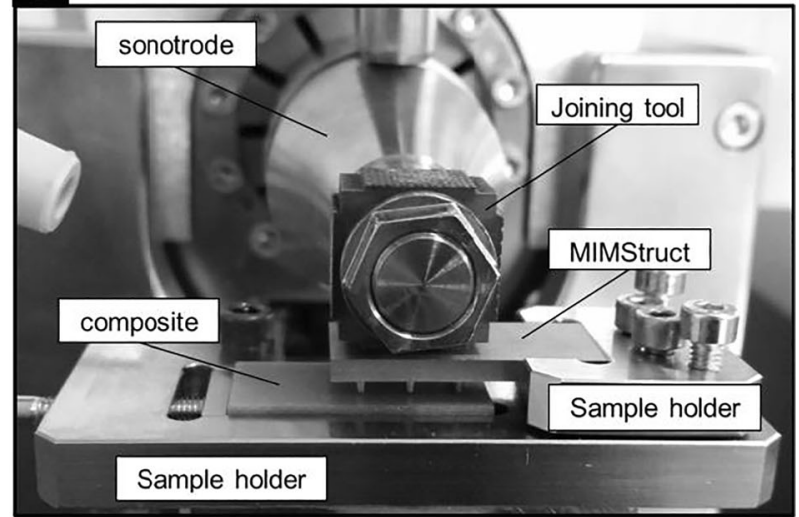

Fig. 4 Sample holder used to produce the U-Joining joints (a) and a detailed picture of its assembling in the joining system (b)

\subsubsection{Statistical modeling, optimization, and model validation}

Multiple regression analysis of the BBD non-linear quadratic model and the analysis of variance (ANOVA) were performed with the Minitab software. Backward elimination of insignificant terms of the model was used to obtain a reduced model without superfluous predictor [30, 32]. The obtained reduced regression models were validated using additional experiments. For that, four validation points were chosen, and the tests were performed in triplicates. The obtained validation results were then compared against model prediction. In Table 5, the validation points are presented, as well as, the optimized condition.

The BBD resultant statistical model was optimized for each factor $\left(E_{J}, A_{0}\right.$, and $J_{P}$ or $x_{1}, x_{2}$, and $x_{3}$ in Eq. 3$)$ to obtained the factors levels that result in the highest ULFS. Such levels are mathematically described by the partial derivatives of $x_{1}, x_{2}$, and $x_{3}$ (i.e., $\frac{\partial \mathrm{ULSF}}{\partial \mathrm{E}_{\mathrm{I}}}=0 \frac{\partial \mathrm{ULSF}}{\partial \mathrm{A}_{0}}=0$ and $\left.\frac{\partial \mathrm{ULSF}}{\partial J_{P}}=0\right)$ [32] and correspond to the Eq. 3 stationary point.

\section{Results and discussion}

\subsection{Typical U-Joining joint microstructural features}

Figure 8 presents the general aspects and microstructural features of a U-Joining joint. After the consolidation phase, the surface-structure pins are completed inserted in the composite part, as shown in Fig. 8a. The microstructural changes during the U-Joining are concentrated mainly at the polymeric part $[12,13]$ due to the thermal stability of Ti-6Al-4V. In this regards, the heat and strain rate associated with the pin feeding creates a thermo-mechanically affected zone (CTMAZ) in the

Fig. 5 Joining tool geometry

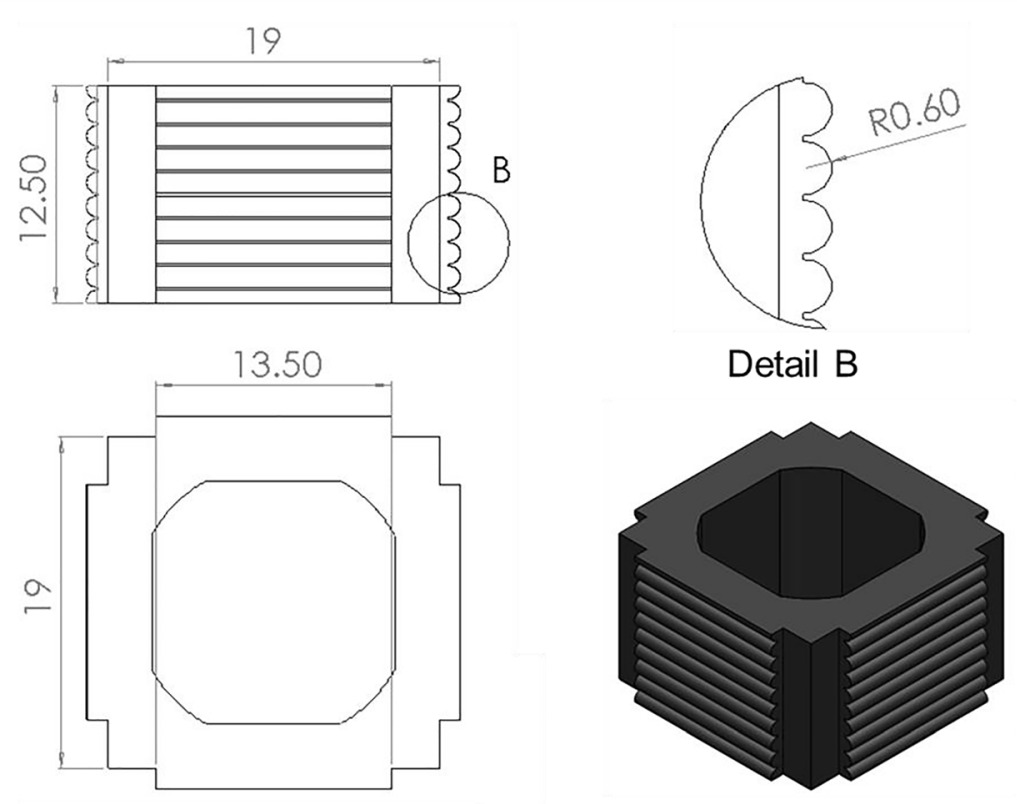


Fig. 6 U-Joining joint geometry. All dimension are presented in millimeters

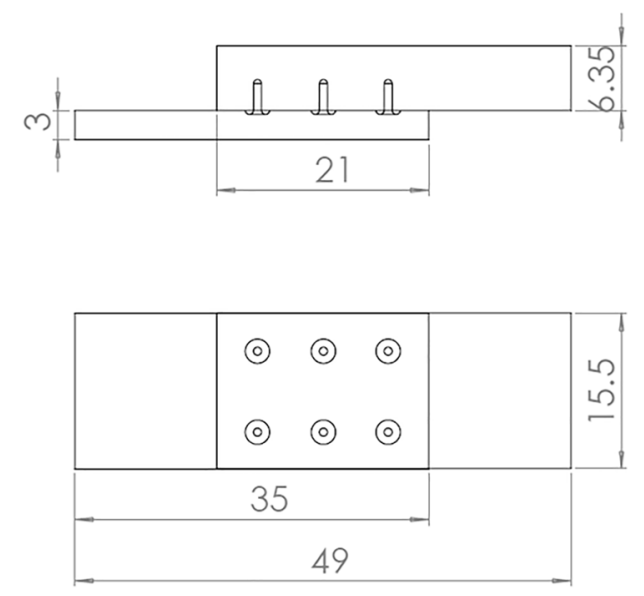

composite part. Such zone corresponds to a thin layer formed at the joint interface distributed around the pins, as schematically illustrated in Fig. 8b, whose geometry is strongly influenced by the joining parameters. At this region, broken fibers, embedded in the molten polymer flowed upwards and filled the pins' undercut (Fig. 8c).

Internal flaws are also typically found in the CTMAZ of UJoining joints, which consist primarily of thermomechanically induced voids (indicated with white arrows in Fig. 8c). These voids might be related to polymer matrix thermal degradation entrapped air bubbles in the viscous soften polymer, and structural water evolution, as usually observed in metal-polymer joining processes [33-35]. In addition, after complete penetration of the pins, part of the CTMAZ glassfiber woven are reoriented upwards from their original plane, as depicted in Fig. 8d.

Apart from the formation of few thermal flaws in the CTMAZ, which are limited to a small region close to the pins, a intimate contact between composite and metal is usually achieved all over the material interface. Figure 8 e depicts the quality of the interface formed between the tip of the pins and composite. Moreover, the soften polymer tends to fill the asperities distributed along the Ti-6Al-4V surface. Consequently, mechanical interlocking at the microscale is achieved, which positively contributes to the joint overall strength. In addition, it was observed that the pins are in very close contact with composite fiber woven, as shown in Fig. 8f, indicating that the consolidation phase was efficient in compensating the differential shrinkage between molten polymer and metal.

\subsection{Effect of joining parameters on the joint mechanical performance}

Changes in the U-Joining parameters can produce a substantial effect on the joint formation, mechanical properties, and in the previously discussed microstructural features. Figure 8 presented the effect of process parameters changes on the joint ULSF. It was observed during the BBD tests that the UJoining joint ULSF varied from just a few Newton up to $3.3 \mathrm{kN}$. In addition, joint geometrical features are affected by changes in the joining parameters, which might result, for instance, high LoP of the TTR. According to the BBD experiments, LoP can vary from high values, $2.8 \mathrm{~mm}$ (i.e., small penetration of TTR) up to a complete insertion (i.e., LoP $\approx 0$ ). Figure 9 presents the variation of LoP and ULSF for all the 15 BBD-based experiments and the three replicates at the design central point $(\mathrm{CP})$.
Fig. 7 U-Joining geometrical features measured by $\mu \mathrm{CT}$ in this work. a Pin deflection and $b$ lack of penetration (LoP)
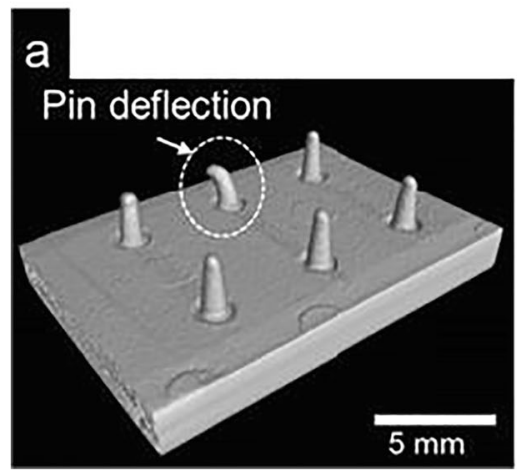

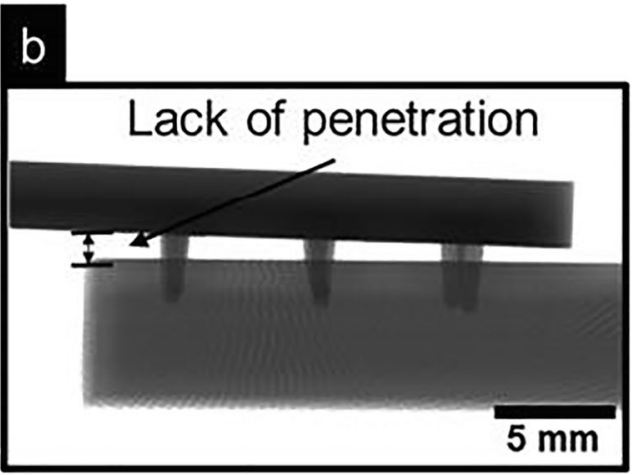


Table 3 BBD factors and their variation levels

\begin{tabular}{lll}
\hline Factors & Symbol & Levels \\
\hline Joining energy $(J)$ & $E_{J}$ & 1200,1800, and 2400 \\
Amplitude $(\mu \mathrm{m})$ & $A_{0}$ & 32,42, and 52 \\
Joining pressure (psi/bar) & $J_{P}$ & 10,15, and 20/0.7, 1.05, and 1.4 \\
\hline
\end{tabular}

By looking close to the obtained experimental data, it can be observed that high values of ULSF are correlated with low LoP. For instance, if we take conditions 3 and 13 as examples, one can see that for the former, a low value of ULSF is associated with a high LoP. While for the condition 13 the opposite behavior is evident. Such trend is observed for all the tested condition. Indeed, if the values of ULSF are plotted against the LoP, as presented in Fig. 10, one can see that both responses are linearly correlated. This correlation can be assessed by fitting a linear equation as shown in Fig. 10a. The coefficient of correlation obtained by such procedure corresponds to 0.83 , thus, characterizing a strong linear correlation between ULSF and LoP. Selected points over the experimental range were further examined by $\mathrm{X}$-ray $\mu \mathrm{CT}$, providing better visualization of the mentioned correlation, as presented in Fig. 10b. Based on the strong linear correlation between the responses, the ULSF was chosen in this work to describe the effect of process parameter on the properties further.

Figure 11 presents the actual versus predicted diagram of the BBD-based ULSF reduced model, the percentage effect of

Table 4 BBD matrix of experiments

\begin{tabular}{|c|c|c|c|c|c|c|}
\hline \multirow[t]{2}{*}{ Experiment } & \multicolumn{3}{|c|}{ Factors } & \multicolumn{3}{|c|}{ Normalized factors } \\
\hline & $E_{J}(\mathrm{~J})$ & $A_{0}(\mu \mathrm{m})$ & $J_{P}$ (psi/bar) & $E_{J}$ & $A_{0}$ & $J_{P}$ \\
\hline $\mathrm{J} 1$ & 1200 & 32 & $15 / 1.05$ & - & - & 0 \\
\hline $\mathrm{J} 2$ & 2400 & 32 & $15 / 1.05$ & + & - & 0 \\
\hline $\mathrm{J} 3$ & 1200 & 52 & $15 / 1.05$ & - & + & 0 \\
\hline $\mathrm{J} 4$ & 2400 & 52 & $15 / 1.05$ & + & + & 0 \\
\hline $\mathrm{J} 5$ & 1200 & 42 & $10 / 0.7$ & - & 0 & - \\
\hline $\mathrm{J} 6$ & 2400 & 42 & $10 / 0.7$ & + & 0 & - \\
\hline $\mathrm{J} 7$ & 1200 & 42 & $20 / 1.4$ & - & 0 & + \\
\hline $\mathrm{J} 8$ & 2400 & 42 & $20 / 1.4$ & + & 0 & + \\
\hline J9 & 1800 & 32 & $10 / 0.7$ & 0 & - & - \\
\hline $\mathrm{J} 10$ & 1800 & 52 & $10 / 0.7$ & 0 & + & - \\
\hline J11 & 1800 & 32 & $20 / 1.4$ & 0 & - & + \\
\hline $\mathrm{J} 12$ & 1800 & 52 & $20 / 1.4$ & 0 & + & + \\
\hline $\mathrm{J} 13$ & 1800 & 42 & $15 / 1.05$ & 0 & 0 & 0 \\
\hline J14 & 1800 & 42 & $15 / 1.05$ & 0 & 0 & 0 \\
\hline $\mathrm{J} 15$ & 1800 & 42 & $15 / 1.05$ & 0 & 0 & 0 \\
\hline
\end{tabular}

Table 5 BBD validation experiments and optimized condition

\begin{tabular}{lllll}
\hline Experiment & $E_{J}(\mathrm{~J})$ & $J_{P}(\mathrm{psi})$ & $A_{0}(\mu \mathrm{m})$ & $t(\mathrm{~s})$ \\
\hline V1 & 1200 & $15 / 1.05$ & 52 & $0.78 \pm 0.15$ \\
V2 & 1600 & $15 / 1.05$ & 52 & $0.85 \pm 0.07$ \\
V3 & 2000 & $15 / 1.05$ & 52 & $1.05 \pm 0.09$ \\
V4 & 2400 & $15 / 1.05$ & 52 & $1.24 \pm 0.07$ \\
Optimized condition & 2012.1 & $14.7 / 1.01$ & 52 & $1.09 \pm 0.03$ \\
\hline
\end{tabular}

each process parameter investigated in this work (i.e., $E_{J}, A_{0}$, and $J_{P}$ ), and their respective second-order significant interaction (i.e., $E_{J}^{2}$ and $J_{P}{ }^{2}$ ). The interaction between each process parameter and their second-order interaction is described by the reduced equation as follows:

$$
\begin{aligned}
U L S F= & -17600+11.27 \times E_{J}+903 \times J_{P}+65.6 \\
& \times A_{0}-0.002801 \times E_{J}^{2}-30.7 \times J_{P}{ }^{2}
\end{aligned}
$$

The estimation of each equation regression coefficient was obtained as described in Sect. 3.5 by a multiple regression analysis of the BBD non-linear quadratic model. In addition, the effect of each significant factor was achieved by ANOVA applying a backward elimination procedure of insignificant terms of the model (i.e., $p$ values smaller than 0.05 ). The obtained ULSF model has an $R^{2}$ of $82 \%$ and an adjusted $\left(R_{\text {adj }}^{2}\right)$ of $72 \%$. Therefore, the model is more prone to fit the data within the experimental range than predict new values outside the experimental range. Nevertheless, all points in the actual versus predicted diagram (Fig. 11a) lied within the 95\% confidential interval. Hence, one can conclude that the obtained ULSF model presents a satisfactory explanatory power and can be applied to further understanding of the effect of process parameters in the ULSF.

The model display major contributions of $E_{J}$ and $A_{0}$ on the ULSF, which corresponds to $25.3 \%$ and $21.2 \%$, respectively (Fig. 11b). Whereas the individual effect of $J_{P}$ was low, although its second-order interaction $\left(J_{P}^{2}\right)$ showed a higher contribution (13.6\%). The average $E_{J}$ presents a positive contribution in the ULSF when increased from 1200 up to $2012 \mathrm{~J}$, as shown in the mean effect plot in Fig. 12a. Above $2012 \mathrm{~J}$, the ULSF starts to decrease with the increase of $E_{J}$. Similarly, the $J_{P}$ individual effect also depicts a peak of maximum, which was observed around $15 \mathrm{psi}$ (1.05 bars), while the increase of $A_{0}$ contributes always positively to the increase of ULSF. Such observations are believed to be closely related with the joint formation mechanisms and its resultant microstructure; therefore, these correlations are systematically elucidated next.

According to the energy-controlled mode employed to adjust the $E_{J}$ delivering during the U-Joining, low $E_{J}$ values 

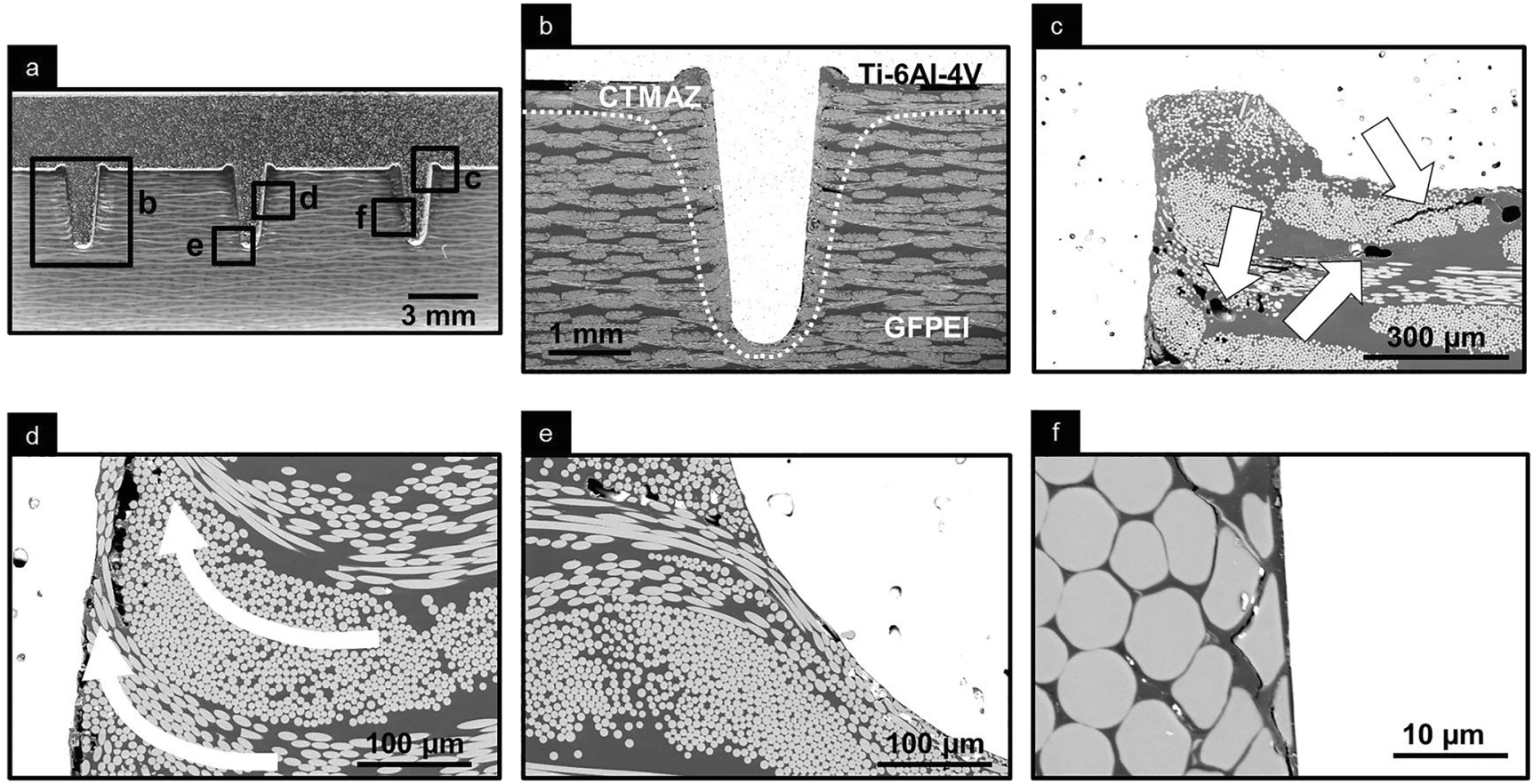

Fig. 8 Typical microstructural features of an U-Joining joint. a Photography of the cross-sectioned samples extracted from the joint o-

reorientation due to the squeezed material flow. e Close contact between verlapped area. b SEM micrograph of pin. $\mathbf{c}$ Undercut filling and formation of thermal-induced voids. d Micrography showing the fiber pin and composite at the interface. f High magnification of a close contact between glass-fiber reinforcement and metallic pin

result in short joining cycles. Such short joining cycles do not provide enough frictional heat at the interface between the pin tips and composite. As a result, a small volume of composite matrix is softened during the joining and, the pin penetration is not completely accomplished. This phenomenon can be observed by the $\mu \mathrm{CT}$ analysis presented in Fig. $12 \mathrm{~b}$ for joints produced with $1200 \mathrm{~J}$ and $2400 \mathrm{~J}$ (i.e., condition $\mathrm{J} 1$ and $\mathrm{J} 2$, respectively). On the other hand, the decrease in ULSF observed for $E_{J}$ levels above $2012 \mathrm{~J}$, Fig. 12a, is most probably related with the increase of the process-affected zones. As earlier presented, at this zone, high volume of thermomechanically induced flaws are found, which might negatively affect the load transfer between the materials, thereby decreasing the ULSF. The increase of thermal-induced flaws in friction-based joining process caused by the increase in heat input has been reported in the literature [36, 37] for of AA2024/PEI hybrid joints, which is correlated with higher processes temperatures.

Although the $J_{P}$ mean effect has a similar consequence on the ULSF, as observed for the $E_{J}$, its physical implication are different. Logically, the higher the $J_{P}$, the higher is the expected pin penetration (i.e., lower LoP), which in turn should result in higher ULSF, as described by the linear between USLF and LoP, Fig. 12. However, it is also expected that, at certain $J_{P}$ levels, the axial pressure applied by the sonotrode during the joining might be high enough to damage the TTR. Such threshold is believed to occur at values closed to $15 \mathrm{psi}$ (1.05 bars), as shown in Fig. 12a. While $E_{J}$ and $J_{P}$ displayed both a point of maximum, the mean effect of $A_{0}$ is always positive in the ULSF. Suggesting that high amplitude values
Fig. 9 Effect of different joining condition on the ULSF and LoP. Where 1 to 15 correspond the $\mathrm{BBD}$ experiments and $\mathrm{CP}$ the central point average

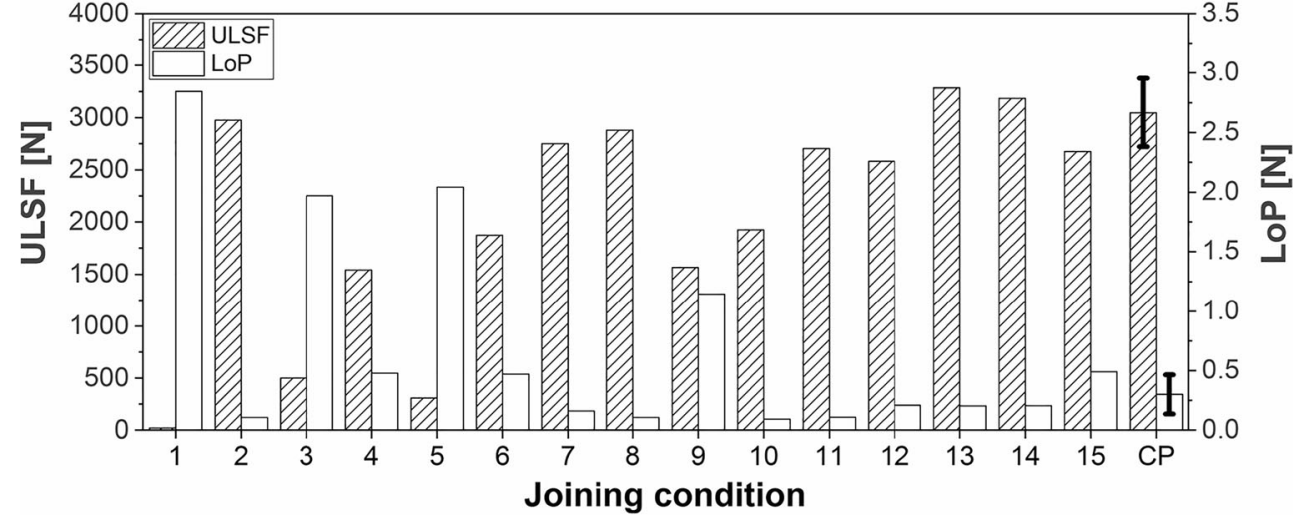


a)

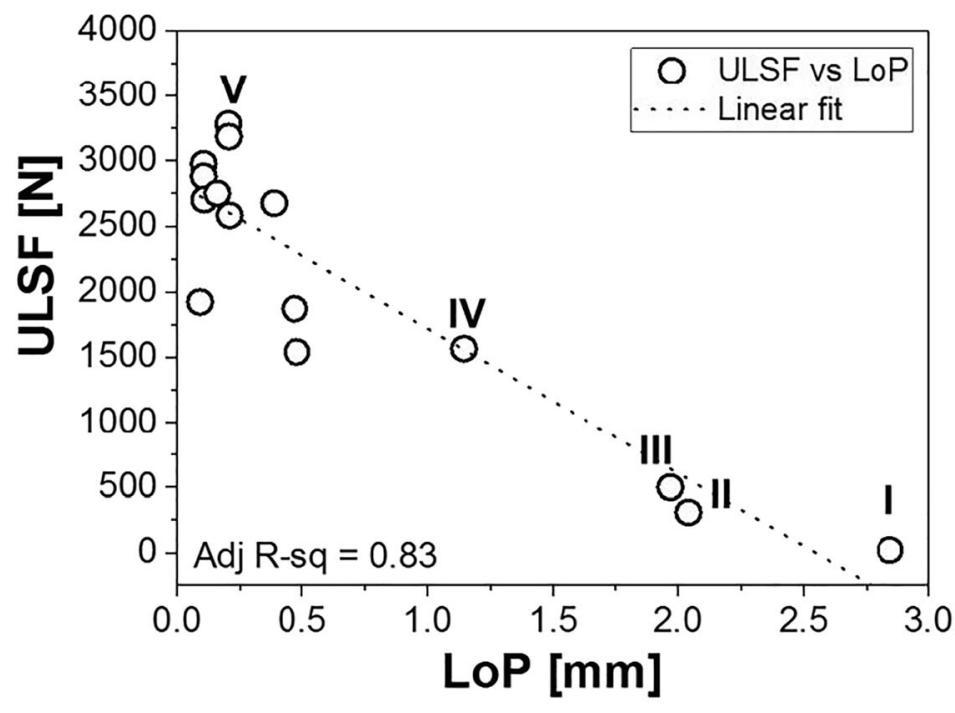

b)
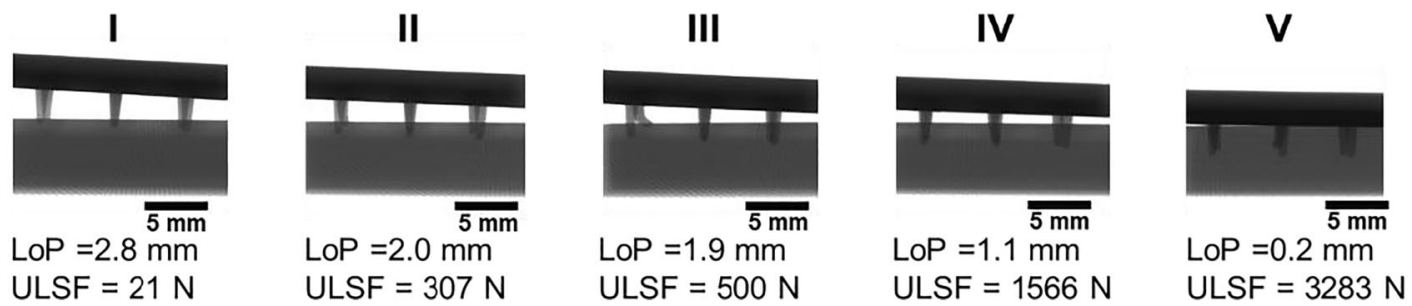

Fig. 10 Linear correlation between ULSF and LoP (a) and X-ray tomography of five selected points distributed over the experimental range investigated (b), showing the effect of LoP in the overlap area

contribute to an effective frictional heating generation at the material interface, which might soften a higher volume of composite matrix, therefore, contributing to a smooth penetration of the pins. It is worth to mention that such individual analysis of parameters on the ULSF might not always reflect accurately the system under investigation since the combination of parameters also played a significant role on the ULSF.
In order to account for the interaction effect between the process parameter, response surfaces of two-way interactions were plotted and are presented in Fig. 13. Moreover, to deliver a visual interpretation of the experimental range limits selected X-ray tomography and 3D-reconstructed $\mu \mathrm{CT}$ of the produced hybrid joints are also shown in Fig. 13. The response surface created by the combined effect $E_{J}$ and $J_{P}$ displays well a)

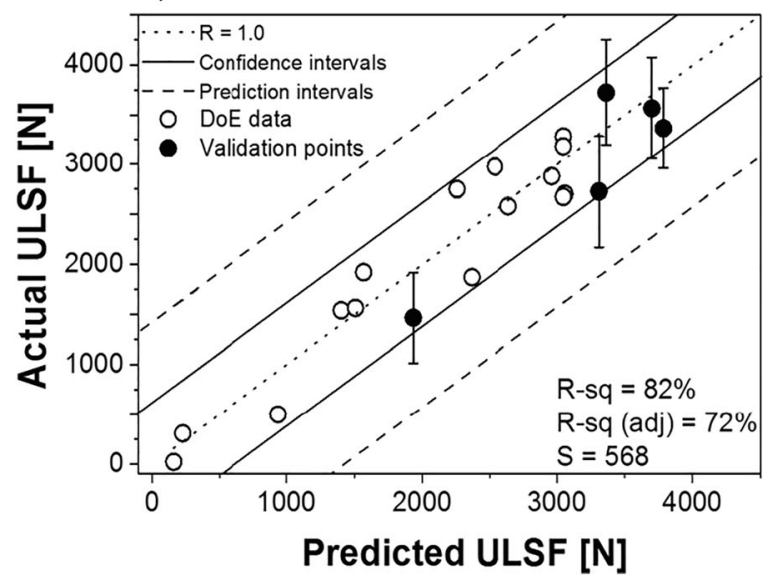

b)
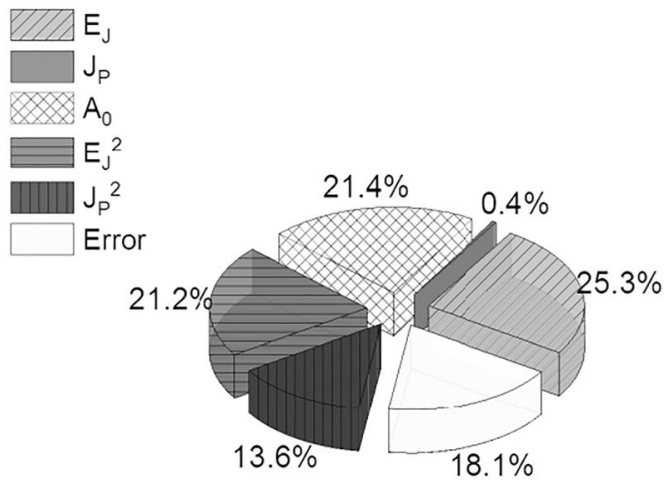

Fig. 11 Actual versus predicted diagram for the ULSF reduced model (a) and effect of each significant factor on the ULSF (b) 
Fig. 12 Plot of the mean effect of the process parameters on the ULSF (a) and selected X-ray tomographies of low and high limits of each individual parameter investigated within the $\mathrm{BBD}(\mathbf{b})$

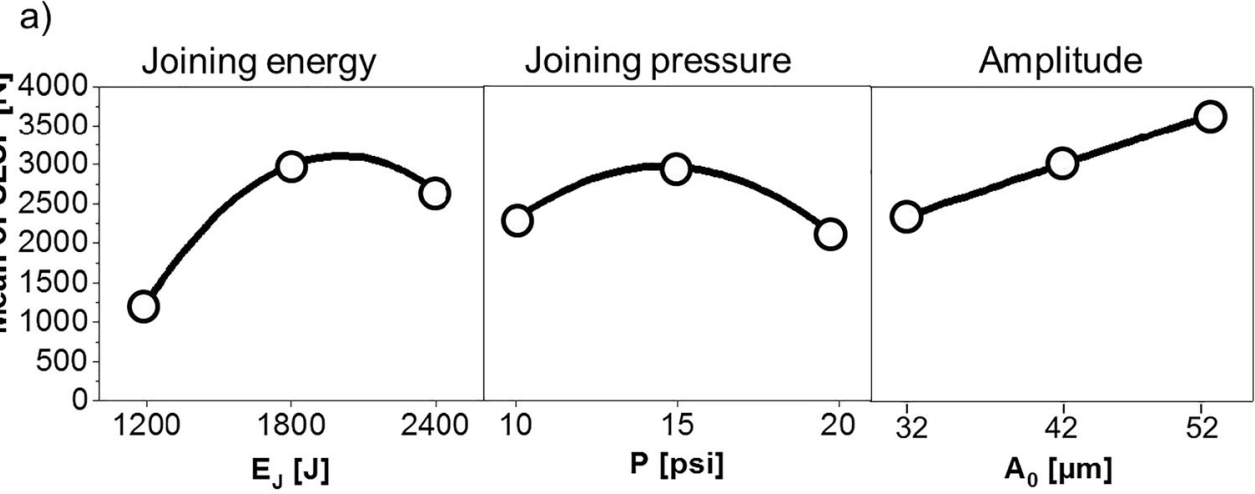

b)
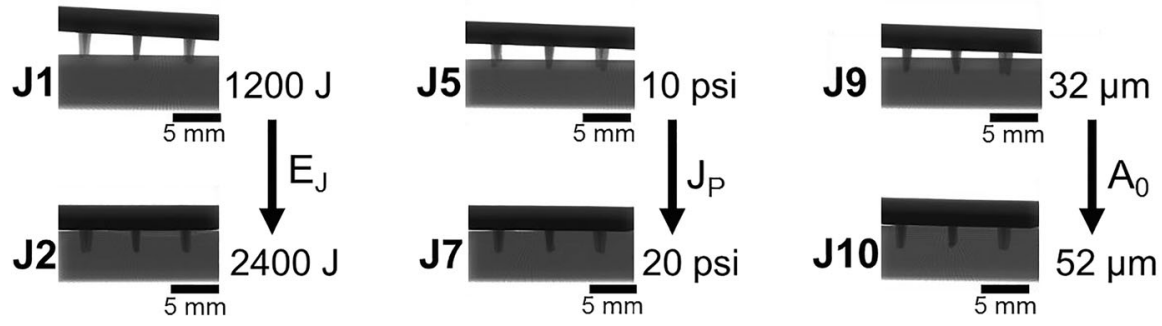

defined region of maximum and its contour system consists of concentric ellipses. By combining low $E_{J}$ and $J_{P}$ levels (P1, Fig. 13a), while keeping the amplitude at the middle level, not enough frictional heat is produced; thereby, a complete penetrate the pins was not accomplished. Consequently, it results in low ULSF. On the other hand, combination of high values of $E_{J}$ and $J_{P}$ results in the central pin deflection, decreasing the USLF. In addition, combined high values of $E_{J}$ and $J_{P}$ might increase the CTMAZ extension and the amount of thermalinduced flaws, which contributes to the decrease in joint mechanical performance. Thus, in order to achieve maximum ULSF, a combination of $E_{J}$ and $J_{P}$ at high and low levels should be avoided.

The combination of $A_{0}$ and $E_{J}$ (Fig. 12b), as well as, $A_{0}$ and $J_{P}$ (Fig. 13c), results in a rising ridge response surface. In such surfaces, the maximum ULSF is not clearly defined, suggesting that it is outside the experimental range. However, it is important mentioning that the joining equipment is limited to an $A_{0}$ of $52 \mu \mathrm{m}$. Consequently, values above it are not experimentally possible. By adopting a similar approach to describe the $A_{0}$ versus $E_{J}$ response surface (Fig. 13b), the combination of parameters at high and low limits are closely investigated. Combination of parameters at low level result in an insufficient heat generation, thereby, joint with considerable high LoP are produced, as shown in the P1 of Fig. 13b, whereas high levels of $A_{0}$ and $E_{J}$ lead to complete penetration of the pin (P2, Fig. 13b). Although, such high values of $E_{J}$ induced excessive heat generation, which might result in higher amount of defects in the CTMAZ. As a consequence, the load transfer capability between the materials decreases, and the maximum ULSF is not achieved. Such ULSF maximum is achieved, therefore, by combining high $A_{0}$ with moderate $E_{J}$ values.

Similar to the previous surface, the response surface created by combine $A_{0}$ and $J_{P}$ displayed a maximum ULSF value combining high $A_{0}$ with moderate to high $J_{P}$ values, Fig. $13 \mathrm{c}$. Low values of such parameters led also to joint with high LoP (P1, Fig. 13c), thereby low ULSF, whereas the combination of high levels of $A_{0}$ and $J_{P}$ induces an aggressive vibrational condition to the pins. As a result, it causes their deflection, as shown in the 3D-reconstruded $\mu \mathrm{CT}$ image of the joint metallic part (P2, Fig. 13c).

\subsection{Statistical model validation and process parameter optimization}

In order to validate the obtained reduced model, four validation experiments plus a joint with the statistical optimized process parameters were performed. Table 6 summarizes the process parameters and the respective responses for the mentioned experiments. The average of actual versus predicted values for the validation points and optimized condition were previously plotted in Fig. 11 (black circles). It is worth to mention that all points lie within the $95 \%$ confidential interval, proving the reliability of the model to predict process parameters within the experimental range investigated in this work. The validation points were systematically selected to display the effect of the joining energy on the joint ULSF and LoP. Figure 14 presents the average ULSF and LoP plotted against the validation points. As previously mentioned both responses 

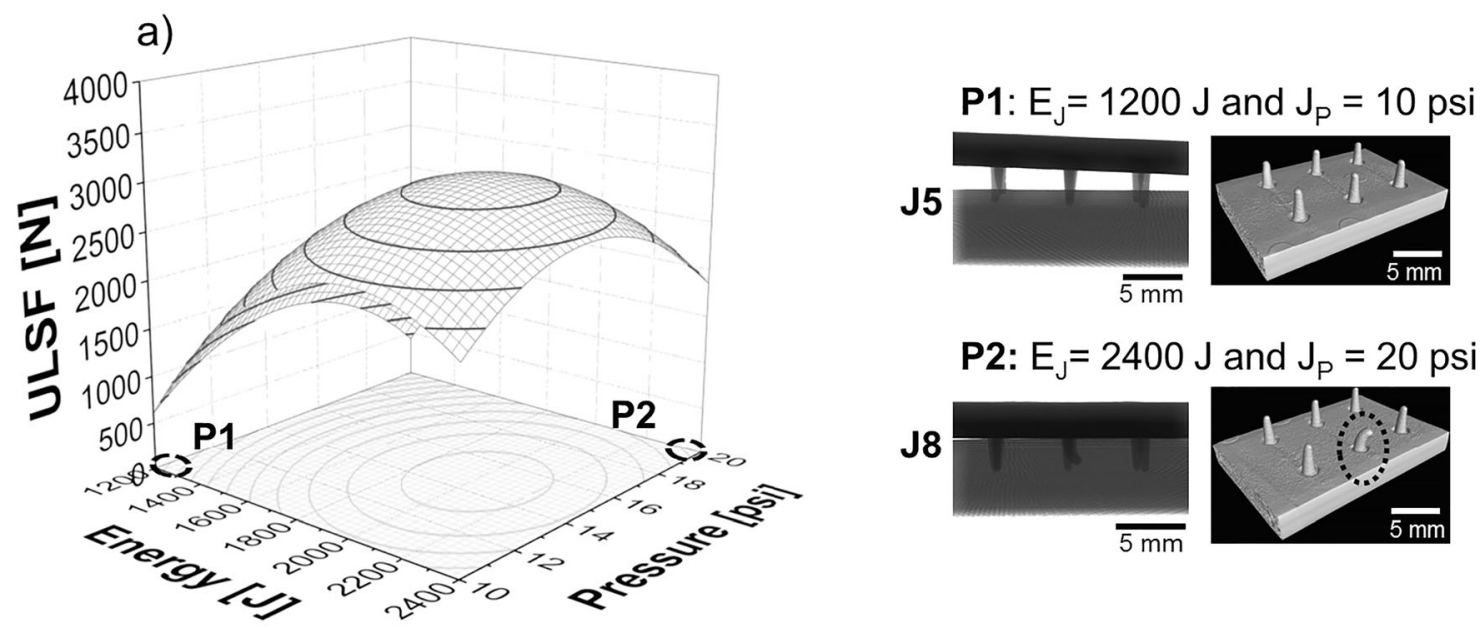

$$
\text { P2: } E_{J}=2400 \mathrm{~J} \text { and } \mathrm{J}_{\mathrm{P}}=20 \mathrm{psi}
$$

J8
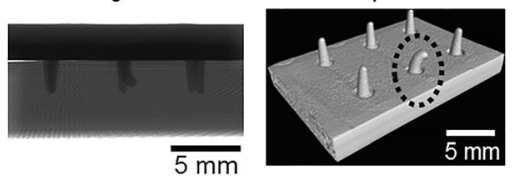

b)
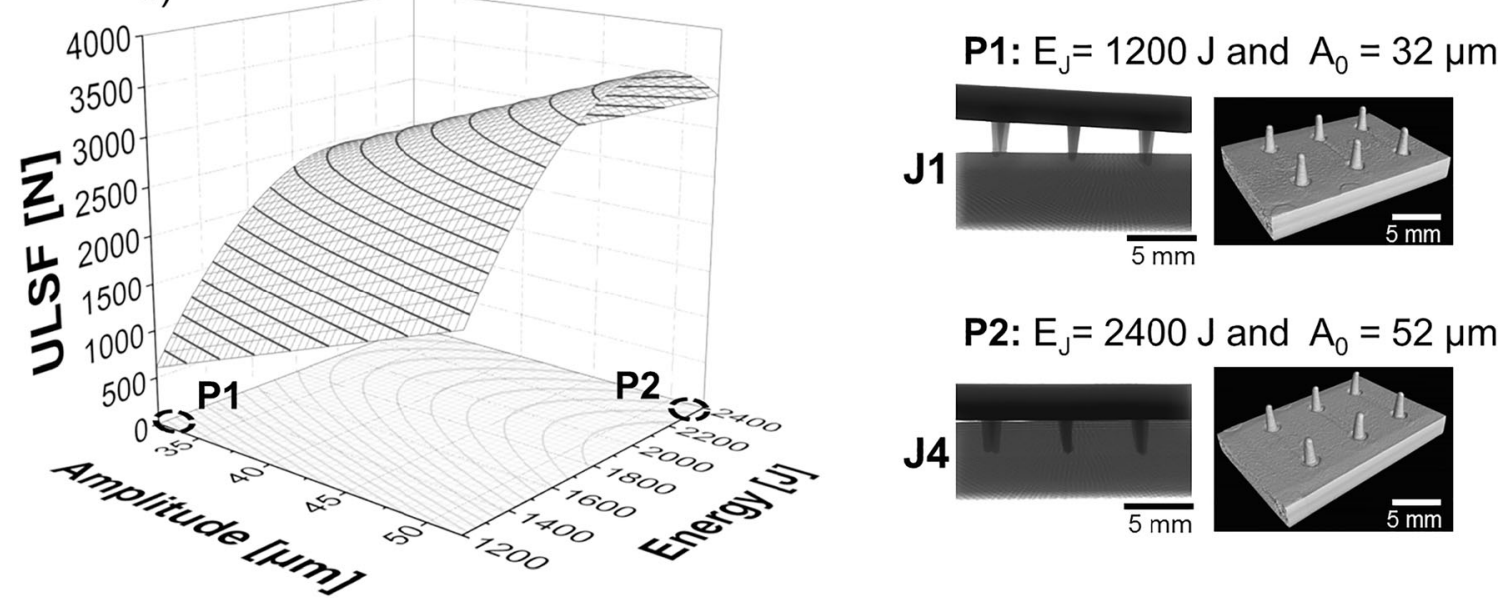

P2: $E_{\jmath}=2400 \mathrm{~J}$ and $A_{0}=52 \mu \mathrm{m}$
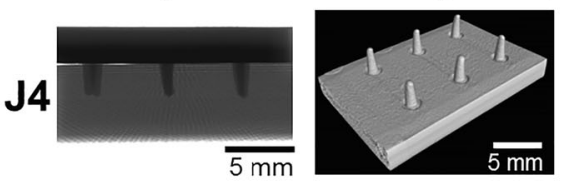

c)

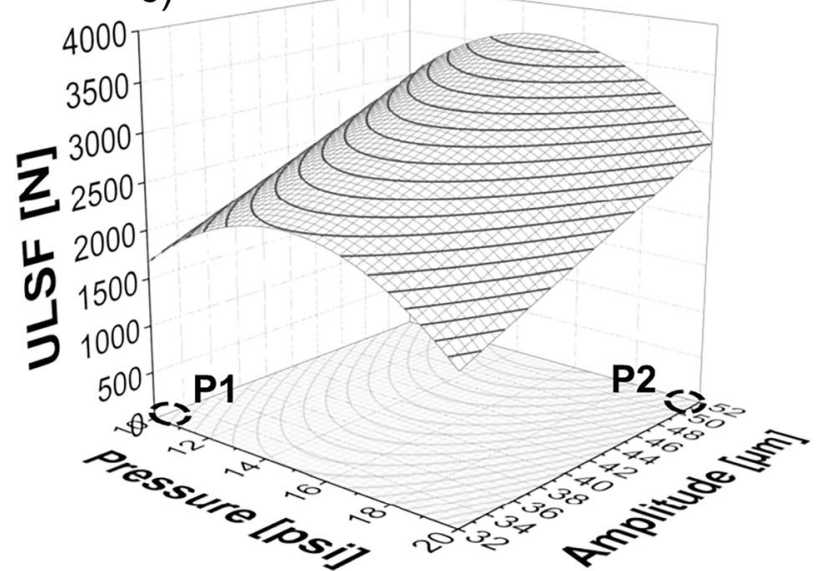

P1: $A_{0}=32 \mu \mathrm{m}$ and $J_{P}=10 p s i$

J1

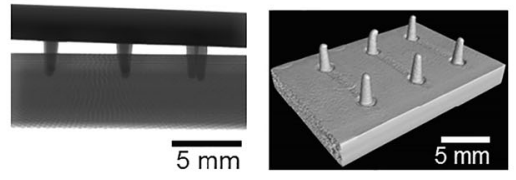

P2: $A_{0}=52 \mu \mathrm{m}$ and $J_{P}=20$ psi
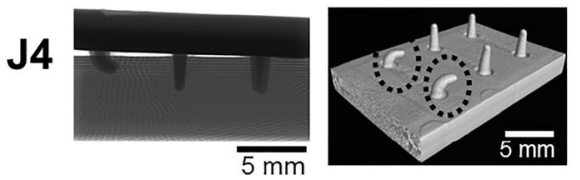

Fig. 13 Surface responses of two-way interactions. Where surface a describes the effect of energy and pressure on the ULSF, $\mathbf{b}$ amplitude and energy, and $\mathbf{c}$ pressure and amplitude. At the right-hand side of each

are inversely correlated and energy values above $2000 \mathrm{~J}$ are sufficient to ensure a satisfactory penetration of the TTR. This response surface, selected X-ray tomography and 3D-reconstructed $\mu \mathrm{CT}$ of the hybrid joint and joint metallic part, respectively, are provided to support the understanding of process parameters on the ULSF

can be associated with enough thermal energy being created; higher polymer matrix plasticization will occur allowing for 
Table 6 Selected validation experiments and optimized parameters

\begin{tabular}{|c|c|c|c|c|c|}
\hline Joining condition & $E_{J}(\mathrm{~J})$ & $J_{P}$ (psi/bar) & $A_{0}(\mu \mathrm{m})$ & $\operatorname{ULSF}(\mathrm{N})$ & $\mathrm{LoP}(\mathrm{mm})$ \\
\hline V1 & 1200 & $15.0 / 1.05$ & 52 & $1466 \pm 452$ & $0.52 \pm 0.43$ \\
\hline $\mathrm{V} 2$ & 1600 & & & $2729 \pm 557$ & $0.41 \pm 0.25$ \\
\hline V3 & 2000 & & & $3366 \pm 404$ & $0.19 \pm 0.05$ \\
\hline V4 & 2400 & & & $3723 \pm 527$ & $0.04 \pm 0.05$ \\
\hline Optimized & 2012.1 & $14.7 / 1.01$ & 52 & $3608 \pm 417$ & $0.10 \pm 0.05$ \\
\hline
\end{tabular}

an easier TTR penetration. Therefore, at lower energies (i.e., at $1200 \mathrm{~J}$ and $1600 \mathrm{~J}$ ), LoP and its standard deviation is larger, decreasing ULSF.

The analysis performed so far provided a detailed comprehension of the effect of the U-Joining process parameters on the joint ULSF, as shown through the analysis of the response surfaces. In this regards, strategies to reach the maximum ULSF were primarily drawn based on the analysis of each two-way interaction surface, providing an insightful tool to set the joining parameters. However, the exact level of each process parameter, which would provide the U-Joining joints with highest ULSF is not directly attained from such analysis. In order to find these process parameter levels the partial derivatives $\partial \mathrm{ULSF} / \partial \mathrm{E}_{\mathrm{J}}=\partial \mathrm{ULSF} / \partial \mathrm{A}_{0}=\partial \mathrm{ULSF} / \partial J_{P}=0$ of the obtained reduced model (Eq. 4) were calculated. In addition, joints produced with such parameter levels (called optimized condition) were produced and mechanically tested under quasi-static loading. The set of obtained parameter (Table 6) from the mentioned mathematical procedure corresponds to the so-called stationary point. It is important noticing that the partial derivative in relation to $A_{0}$ results in $65.6 \mu \mathrm{m}$, however, the used optimized value in this work was $52 \mu \mathrm{m}$. That is because such amplitude level corresponds to the maximum amplitude achieved by the joining equipment.
Theoretically, the position of the stationary point in a complex surface can represent three hypothesis: (i) it can represent a point of maximum response, (ii) a point of minimum, or (iii) a saddle point $[30,32]$. However, due to the simplicity of the responses from the statistical modeling of the U-Joining process, it is clear that the values obtained correspond to the point of maximum. Such assumption can be easily proved by a quick examination of the stationary point vicinity, drawing the point on the resulting response surfaces. Based on that, it can be concluded that no additional mathematical analysis is required to investigate the nature of the stationary point.

In conclusion, by comparing the optimized joint condition with U-Joining joints produced with the same material combination, previously published in [12], an improvement of $79 \%$ in ULSF can be observed as shown in Fig. 15. Such result emphatically shows the efficiency of the proposed optimization procedure to obtain the best set of joining parameters for the realization of the U-Joining.

\section{Conclusion}

In order to understand the effect of process parameters on the ULSF and optimize the process to produce stronger joints, a
Fig. 14 Effect of joining energy on the ULSF and LoP validation points

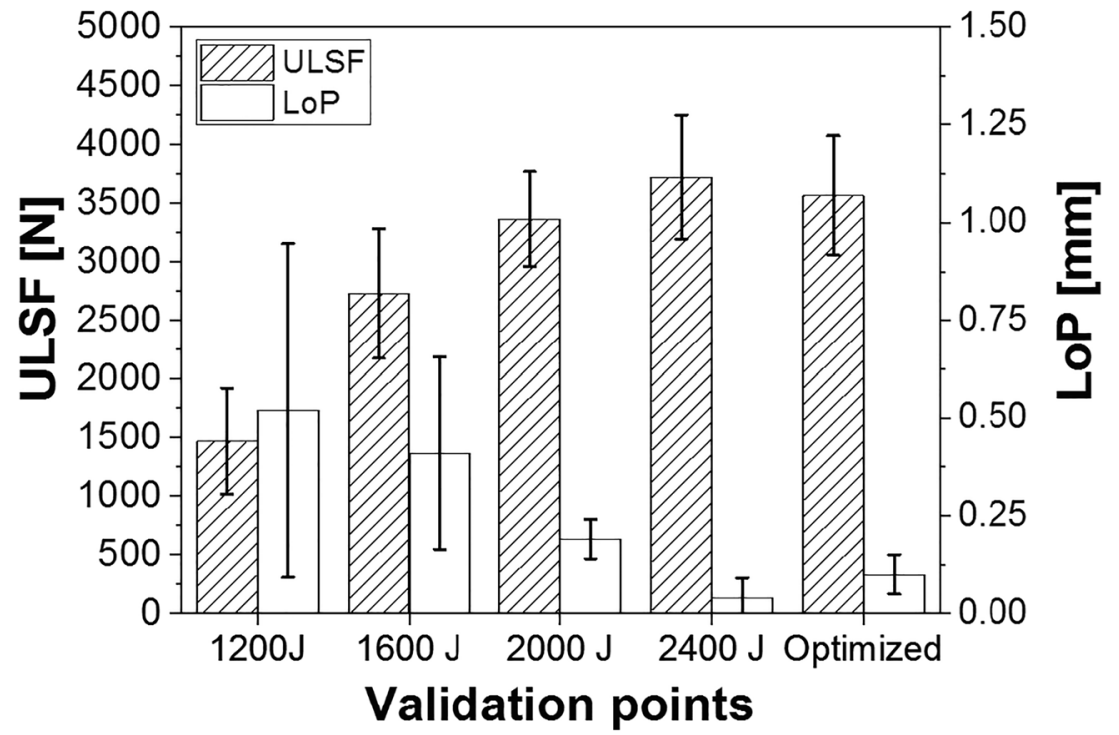




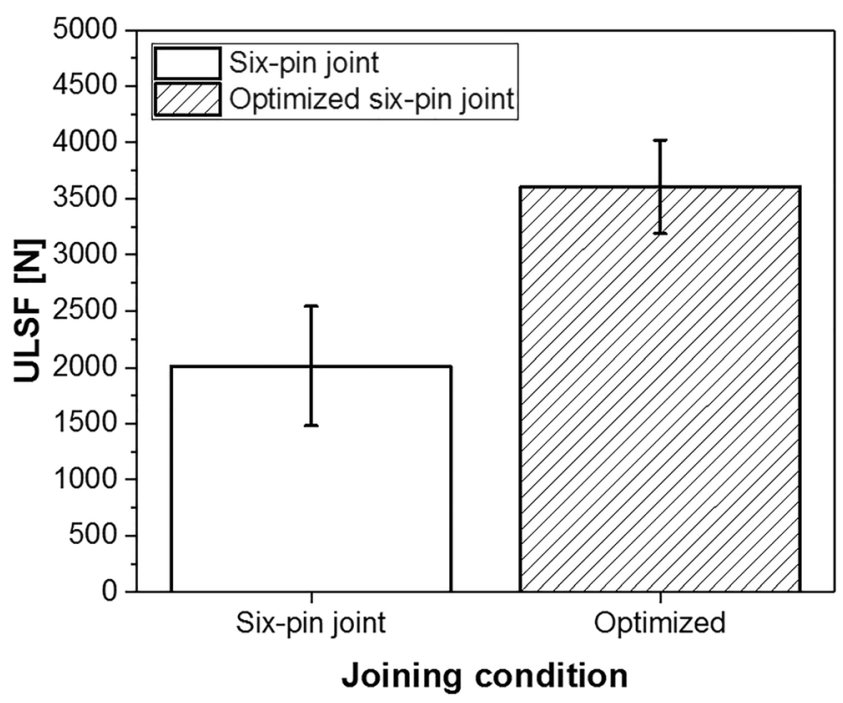

Fig. 15 Comparison of the optimized U-Joining joint with previously published results (i.e., "six-pin joint" reference joints) obtained with the same material combination and joining approach [12]

Box-Behnken design of experiments (BBD) was applied. During the data analysis, it was observed that changes in the U-Joining parameters produced substantial effects on the joint mechanical properties. By applying multiple regression analysis of the $\mathrm{BBD}$, a reduced statistical model that described the interaction between each process parameter and their secondorder interaction was achieved. The reduced model showed an $\mathrm{R}^{2}$ of $82 \%$ and, therefore, considered reliable for the proposed analysis. Thought the plot of the response surface, analysis of the combined effect of joining parameters were obtained and their effect on the joint properties were described based on the $\mu \mathrm{CT}$ results. In addition, by optimizing the obtained reduced model, a set of joining parameters was achieved to produce hybrid joints with above-average mechanical performance among the experiments BBD experiments. In conclusion, by comparing the optimized joint condition with previous UJoining joints joined with the same material combination [12], an improvement of 79\% in ULSF was achieved. Such result emphatically shows the efficiency of the proposed optimization strategy to set the best-joining parameters. The findings can efficiently assist in future U-Joining process development, which might include the application of different material combination and process scale-up. In addition, it shows the potential of the U-Joining concept to manufacturing future lightweight hybrid joints for structural applications with improved mechanical properties.

Acknowledgments Open access funding provided by Graz University of Technology. The authors would like to acknowledge the scholarship of E.E. Feistauer provided by the Conselho Nacional de Desenvolvimento Cientifico e Tecnológico - CNPq, Brazil. S.T. Amancio-Filho gratefully acknowledges financial support from the Austrian aviation program "TAKE-OFF" and from the Austrian Ministry for Climate Action, Environment, Energy, Mobility, Innovation and Technology, BMK, as well as Branson Ultrasonics S.A./Amtech for providing the joining equipment.

Open Access This article is licensed under a Creative Commons Attribution 4.0 International License, which permits use, sharing, adaptation, distribution and reproduction in any medium or format, as long as you give appropriate credit to the original author(s) and the source, provide a link to the Creative Commons licence, and indicate if changes were made. The images or other third party material in this article are included in the article's Creative Commons licence, unless indicated otherwise in a credit line to the material. If material is not included in the article's Creative Commons licence and your intended use is not permitted by statutory regulation or exceeds the permitted use, you will need to obtain permission directly from the copyright holder. To view a copy of this licence, visit http://creativecommons.org/licenses/by/4.0/.

\section{References}

1. WHITE PAPER (2011) Roadmap to a single European transport area - towards a competitive and resource efficient transport system

2. Timmis AJ, Hodzic A, Koh L, Bonner M, Soutis C, Schäfer AW, Dray L (2015) Environmental impact assessment of aviation emission reduction through the implementation of composite materials. Int J Life Cycle Assess 20:233-243

3. Amancio-Filho ST, dos Santos JF (2009) Joining of polymers and polymer-metal hybrid structures: recent developments and trends. Polym Eng Sci 49:1461-1476

4. Amancio Filho ST, Blaga L-A (2018) Joining of polymer-metal hybrid structures: principles and applications. John Wiley \& Sons, Inc

5. Feistauer EE, Amancio-Filho ST (2017) Ultrasonic joining of lightweight alloy/Fiber-reinforced polymer hybrid structures, in: Join. Polym. Hybrid Struct., John Wiley \& Sons, Inc, 307-333

6. Ucsnik S, Gradinger R (2010) Evaluation of a novel lightweight metal-composite- joint technology, 14th Eur. Conf. Compos. Mater.

7. Kellar EJC, Smith F (2005) Comeld - a new approach to damage control for composite to metal joints, Des. Perform. Compos. Mater. Conf.

8. Parkes PN, Butler R, Meyer J, de Oliveira A (2014) Static strength of metal-composite joints with penetrative reinforcement. Compos Struct 118:250-256

9. Ucsnik S, Scheerer M, Zaremba S, Pahr DH (2010) Experimental investigation of a novel hybrid metal-composite joining technology. Compos Part A Appl Sci Manuf 41:369-374

10. Ucsnik SA, Kirov G (2011) New possibility for the connection of metal sheets and Fiber reinforced plastics. Mater Sci Forum 690: $465-468$

11. Schimmack M, Feistauer EE, Amancio-Filho ST, Mercorelli P (2017) Hysteresis analysis and control of a metal-polymer hybrid soft actuator. Energies. 10:508

12. Feistauer EE, Guimaraes RPM, Ebel T, Dos Santos JF, AmancioFilho ST (2016) Ultrasonic joining: a novel direct-assembly technique for metal-composite hybrid structures. Mater Lett 170:1-4

13. Feistauer EE, Ebel T, Santos JF, Amancio-Filho ST (2017) Ultrasonic joining of through-the-thickness reinforced Ti-4Al-6V and polyetherimide hybrid joints, ANTEC® 2017 - Anaheim, Soc. Plast. Eng. Calif. - USA.

14. Amancio-Filho ST, Feistauer EE, dos Santos JF (2016) Method for connecting a surface-structured workpiece and a plastic workpiece, US 2016/0297138 A1 
15. Amancio-Filho ST, Feistauer EE, dos Santos JF (2016) Method for connecting a surface-structured workpiece and a plastic workpiece, European patent, EP 3078480 A1, EP 3078480 A1

16. Welding Handbook Committee (2004) Welding Handbook volume 2, 9th ed., AWS - American Welding Society

17. Grewell DA, Benatar A (2003) Plastics and composites welding handbook, Hanser Gardener

18. Rotheiser J (1999) Joining of plastics: handbook for designers and engineers, 3. Auflage, Carl Hanser Verlag GmbH \& Co. KG

19. Ebel T, de Traglia Amancio Filho S, dos Santos JF (2016) Method for manufacturing metal casings with structured surfaces. European Patent No. EP 2468436 B1

20. Kenneth C (2002) Mills, recommended values of thermophysical properties for selected commercial alloys. Woodhead Publishing

21. ISO 2740:2009 - Sintered metal materials, excluding hardmetals Tensile test pieces, (2009)

22. Tencate, CETEX(R) PEI Datasheet - Tencate advanced composites USA, www.tencate.com (accessed Mar 21, 2018)

23. Product datasheet, Cetex ${ }^{\circledR}$ TC 1000 Premium, TenCate. www. tencate.com (accessed Mar 21, 2018)

24. Duratron U1000 PEI (2011) www.quadrantplastics.com (accessed Mar 21, 2018)

25. UltraWeld L20 (2007) AmTech Product Manual- Special Information

26. Cavazzuti M (2013) Optimization methods: from theory to design scientific and technological aspects in mechanics. Springer, Berlin Heidelberg, Berlin, Heidelberg

27. Zhao Q, Shao Z, Leng Q, Zhang X, Liu C, Li B, Jiang M (2017) Preparation of $\mathrm{Cu}-\mathrm{Cr}$ alloy powder by heat mechanical alloying and Box-Behnken design based optimization. Powder Technol 321: 326-335

28. Balasubramanian M (2015) Application of Box-Behnken design for fabrication of titanium alloy and 304 stainless steel joints with silver interlayer by diffusion bonding. Mater Des 77:161-169

29. Sathyamoorthy N, Magharla D, Chintamaneni P, Vankayalu S (2017) Optimization of paclitaxel loaded poly ( $\varepsilon$-caprolactone) nanoparticles using Box Behnken design. Beni-Suef Univ. J. Basic Appl, Sci

30. Montgomery DC, Runger GC (2003) Applied statistics and probability for engineers, 3rd edn. John Wiley \& Sons

31. Sahoo BK, Chakraborty U, Mukherjee J, Pal TK (2010) Optimization and validation of modulated release formulation of ranitidine $\mathrm{HCl}$ by response surface methodology. J Biomed Sci Res 2:76-85

32. Montgomery DC (1997) Design and analysis of experiments. John Wiley \& Sons, Inc., Fourth

33. Andre N, Goushegir SM, dos Santos J, Canto L, Amancio-Filho ST (2016) Friction spot joining of aluminum alloy 2024-T3 and carbon-fiber-reinforced poly(phenylene sulfide) laminate with additional PPS film interlayer: microstructure, mechanical strength and failure mechanisms. Compos Part B Eng 94:197-208

34. Jung KW, Kawahito Y, Takahashi M, Katayama S (2013) Laser direct joining of carbon fiber reinforced plastic to zinc-coated steel. Mater Des 47:179-188

35. Amancio-Filho ST (2011) Henry Granjon Prize Competition 2009 Winner Category A: "Joining and Fabrication Technology" Friction Riveting: development and analysis of a new joining technique for polymer-metal multi-material structures. Weld World 55: $13-24$

36. Amancio-Filho ST, dos Santos JF (2009) Influence of processing parameters on microstructure and properties of a polyetherimide joined by FricRiveting: investigation of rotational speed, in: ANTEC, 750-756

37. Abibe AB, Amancio-Filho ST, dos Santos JF, Hage E Jr (2013) Mechanical and failure behaviour of hybrid polymer-metal staked joints. Mater Des 46:338-347

Publisher's note Springer Nature remains neutral with regard to jurisdictional claims in published maps and institutional affiliations. 